\title{
STRENGTH ANALYSIS OF A LARGE-SIZE SUPPORTING STRUCTURE FOR AN OFFSHORE WIND TURBINE
}

\author{
Karol Niklas \\ Gdansk University of Technology, Poland
}

\begin{abstract}
The offshore wind power industry is the branch of electric energy production from renewable sources which is most intensively developed in EU countries. At present, there is a tendency to install larger-power wind turbines at larger distances from the seashore, on relatively deep waters. Consequently, technological solutions for new supporting structures intended for deeper water regions are undergoing rapid development now. Various design types are proposed and analysed, starting from gravitational supports (GBS), through monopiles and 3D frame structures (jackets, tripods), and ending with floating and submerged supports anchored to the seabed by flexible connectors, including TLP type solutions.

The article presents the results of examination of an untypical large-size gravitational support intended for waters with the depth of up to $40 \mathrm{~m}$. Firstly, a general concept of the new design is presented, while the next basic part of the article describes the support design in detail and provides its strength analysis. The examined support has the form of a large steel container consisting of conical segments. The strength analysis was conducted using the finite element method (FEM), in accordance with the standard DNVGL-ST-0126. Modifications introduced to the most heavily loaded structural node of the support, which was the set of base bottom trusses, is also included. The results of the performed analysis prove that the presented concept of supporting structure for a $7 M W$ turbine meets fundamental strength criteria. The nonlinear buckling analysis was performed to evaluate the critical force acting on the support, which turned out to be 1.44 times as large as the maximum load of the wind turbine. Potentially important issues for further analyses have been identified as those resulting from the asymmetry of basic loads acting on the support.
\end{abstract}

Keywords: Renewable energy sources, offshore wind power industry, supporting structure, strength analysis, FEM, computer simulation, numerical calculations, CFD, conceptual design, buckling, thin-walled structure

\section{INTRODUCTION}

The offshore wind power industry sector is undergoing rapid development, as a result of EU policy on energy production from renewable sources. In two recent decades, the wind energy conversion technologies have been shifted from a sort of niche sector to one of most dynamically developing power industry branches. Following the publication of EU policy objectives concerning power industry development in years 2020 to 2030 [1], the development of the wind energy sector is included to strategic directions, and a substantial potential for development is seen in offshore installations [2, 3]. The trend in offshore wind power industry development is illustrated by the diagram in Fig. 1, which presents the annual and cumulated power of offshore wind turbines installed in EU countries.

Further dynamic development of this sector will be possible, provided that several technological challenges concerning production and installation of new wind farms of large-power turbines (100 MW and more) will be solved [6]. These farms should be situated at a large distance from the seashore and, consequently, on relatively deep waters. At present, the technological advancement level provides real opportunities for commercial investment project execution only on coastal waters. At the end of 2015, the average distance of wind farms connected to electric networks from the seashore was $43.3 \mathrm{~km}$, and the average water region depth 
was $27.1 \mathrm{~m}$ [4]. The most recent trends in the offshore wind power development are shown in Fig. 2.

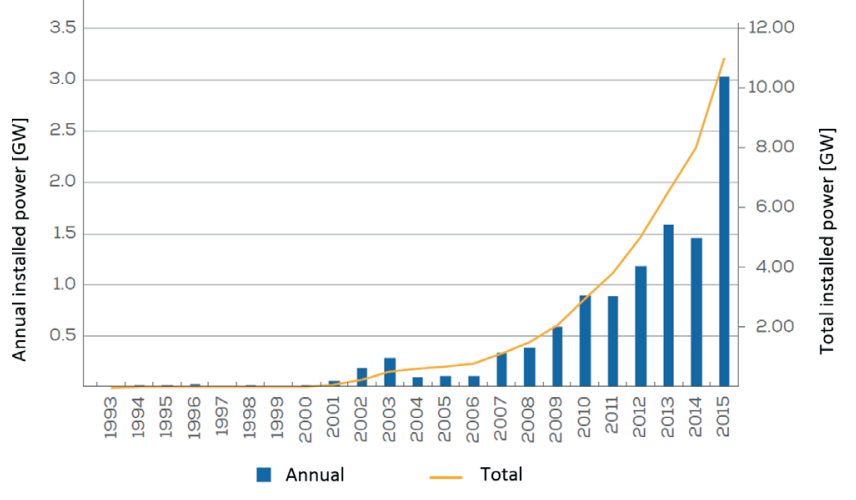

Fig. 1. Annual and cumulated power of offshore wind turbines installed in EU countries UE $[4,5]$

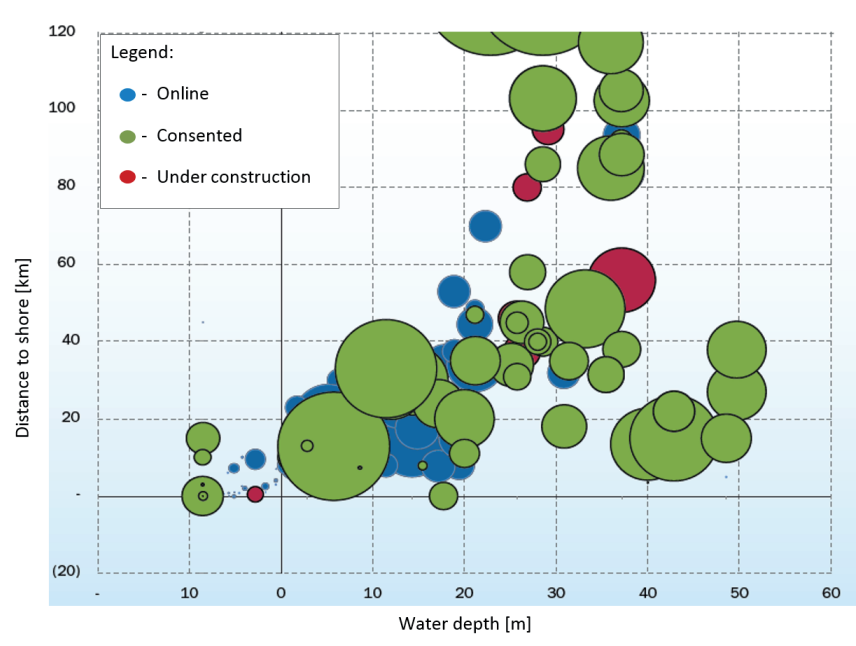

Fig. 2. Average water region depth and distance from the seashore-for wind farms: connected to the electric networks, accepted, and under construction [4]

For water regions with depths of up to $20 \mathrm{~m}$, the most frequently used foundation form is a monopile driven into the seabed, while for the depths exceeding $30 \mathrm{~m}$ several support designs have been adopted from the offshore oil rig industry. The latter supports usually have the form of $3 \mathrm{D}$ frames or tripods. The offshore wind power industry development trends clearly lead towards deeper water regions. However, the main problem here is the lack of effective technical solutions for supporting structures, although the literature on supports for offshore wind turbines provides descriptions of various foundation types, such as monopiles [7-9], tripods $[10,11]$, jackets [12-13], gravitational supports [14-16], etc. The solutions proposed for much larger depths, exceeding $50 \mathrm{~m}$, include floating supports, [17-20], partially or fully submerged supports with flexible connectors [21], and supports with submerged displacement hulls, a so-called Tension Leg Platform (TLP) solution [22-23]. What is noteworthy is huge technological progress in the field of numerical simulations, supported by experimental tests [24-37]. Visible progress is also observed in technologies of structure production [3840] and structure operation monitoring [41-45]. All these factors affect considerably the dynamics of offshore wind power industry sector development.

This article proposes a concept of gravitational type foundation intended for waters with the depth of up to 40 $\mathrm{m}$. For these waters, neither conventional solutions nor concepts of new type floating structures have been used so far. Obviously, the proposed supporting structure can be adapted to other water depths, but this adaptation would require new strength analyses. The general solution concept was proposed within the framework of the research project AQUILO oriented on verifying various concepts for offshore wind turbine foundations on the Baltic Sea. In the present concept, the supporting structure has the form of a large-size thin-walled steel container, ballasted with so-called pulp (mixture of sand and water). The strength analysis for the new support was conducted in accordance with the standard DNVGL-ST-0126 [46]. In the article, Section 2 presents the design assumptions, while Section 3, being the main part of the article, describes the FEM model based strength analysis of the examined structure. The presented results also include the assessment of the critical force coming from wind turbine load, and the presentation of changes introduced to the main structural node of the design. Section 4 provides conclusions from the research and indicates possible directions of its further continuation.

\section{DESIGN ASSUMPTIONS}

The supporting structure is intended for a $7 \mathrm{KW}$ offshore wind turbine to be operated on North Sea or Baltic Sea waters, at the depth of up to $40 \mathrm{~m}$. The structure was designed as a very untypical support of gravitational type, having the form of a thin-walled steel container. The general plan of the support with the installed column and turbine is shown in Fig. 3. The horizontal axis of the turbine is situated $100 \mathrm{~m}$ above the surface level of the 40-meter deep water region. The design also includes a 70-meter high intermediate column, similar to that used in monopile designs. This column rests on the foundation consisting of three conical segments. The end cross-sections of the first 30-meter high cone have the shapes of regular dodecagons inscribed in circles of $5.5 \mathrm{~m}$ (top) and $7.0 \mathrm{~m}$ (bottom) in diameters. The next segment, situated below, increases the diameter of the circle in which the regular bottom cross-section dodecagon is inscribed to $12.0 \mathrm{~m}$, while the base of the lowest segment, lying on the seabed, is inscribed in the circle of $40 \mathrm{~m}$ in diameter.

While typical gravitational supports are made of concrete $[16,47]$, the presented structure is designed in the form of a thin-walled steel container. The structural shape of the container is similar to that of stiffened panels used in modern shipbuilding and offshore industry. The article describes the research activities concerning the support segment to the height of $70 \mathrm{~m}$ above seabed (underwater part and intermediate column). The support is designed as a container, playing the 
function of a displacement hull, which is delivered to the foundation place via towing. Then the support is submerged by flooding the ballast tanks. Proper stability of the support standing on the seabed is ensured by ballasting the container with pulp to the height of $25 \mathrm{~m}$. Other ways of transport and setting of the support seem to be more difficult and more expensive. The assumer lifetime of the support is 50 years.

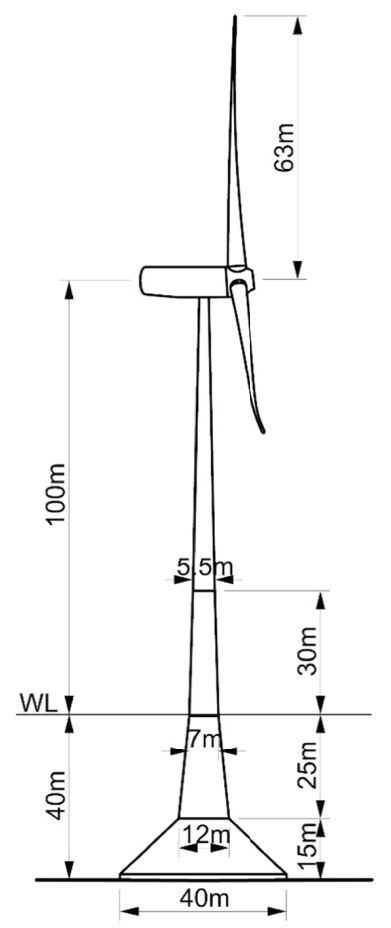

Fig. 3. General plan of the concept of gravitational supporting structure (steel container with internal ballast)

\section{STRENGTH ANALYSIS OF THE UNTYPICAL OFFSHORE WIND TURBINE SUPPORTING STRUCTURE}

The strength analysis was conducted in accordance with the standard DNVGL-ST-0126 [46]. The designed structure was subjected to maximal loads calculated for the assumed location and time of operation. The calculations were performed using the FEM model and the ANSYS software. The environmental loads were calculated with the aid of computational fluid dynamics (CFD) codes and the simulation platform STAR-CCM+. Sections 3.1 to 3.4 present the obtained strength analysis results, while the main results of maximal deflection and stress calculations are shown in Section 3.5, along with the calculated critical force which initiates buckling. This force was assessed by increasing the maximal wind turbine load until the load capacity limit was obtained. To meet requirements included in relevant regulations, some changes were introduced to the most heavily loaded structure fragments. The multi-variant analysis of the effect of selected design parameters on the support strength was also performed to decrease the level of global column deflections and local stresses in the structure.

\subsection{AIM OF ANALYSIS}

The strength analysis aimed at verifying the overall strength of load carrying elements of the untypical offshore wind turbine supporting structure. An important element of the analysis was identifying most heavily loaded regions and introducing changes to the initial design of the structure to reduce maximal support deflections and stresses at most heavily loaded structural nodes. The final stage of the analysis was calculating the critical force and identifying structure destruction forms.

For the purpose of strength calculations, the FEM model of the examined support was created. The support structure was modelled using shell elements, while the intermediate column was modelled using beam elements, and the nacelle was modelled using the mass element.

The numerical model of the support having the form of a large-size thin-walled container was based on shell elements (shell181), which are four-node elements with 6 degrees of freedom at each node. The FEM model described the geometry of the examined object very precisely. The elementary grid size was $150 \mathrm{~mm}$, and respected the principle of at least three nodes over the span of each structural element. Modelling low stiffeners with the aid of shell elements provided the opportunity to connect the stiffener nodes with those of the truss webs through which they pass. This enabled more precise modelling of conditions of cooperation between these elements in the global model. Structural elements which were not involved in carrying global loads, inner walls in ballast tanks for instance, were excluded from the analysis. The FEM model of the examined offshore wind turbine supporting structure is shown in Fig. 4.
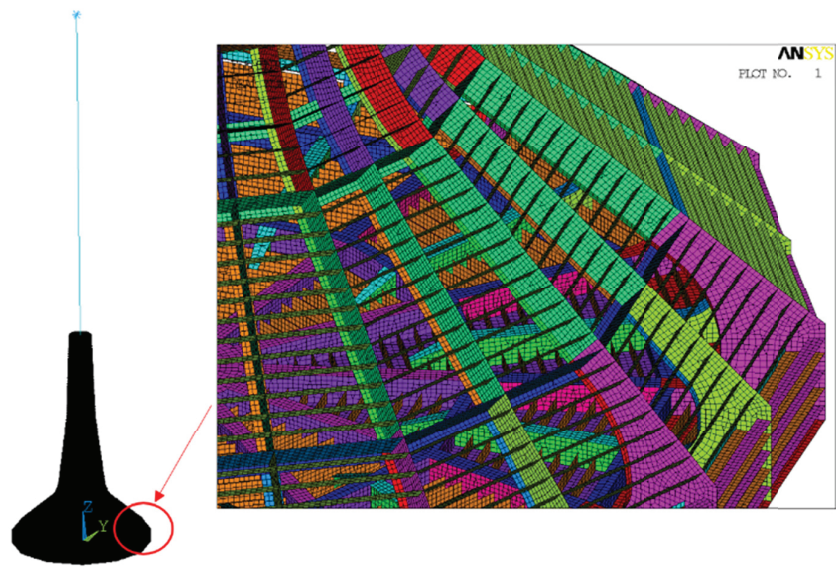

Fig. 4. FEM model of the offshore wind turbine supporting structure (hidden external plating) 


\subsection{MATERIAL MODEL}

The structure of the support was designed to be made of normal-strength steel, Category $\mathrm{B}$, according to the requirements in the standard DNV-OS-B101 [48]. Chemical composition and strength of this material, labelled as S235J0, meet the requirements of the standard EN 10025-2 [49]. At the same time the most heavily loaded region of the supporting structure, which is the passage of vertical trusses into base bottom trusses, was designed to be made of higher-strength steel NV A27, Category A, for truss webs, and of high-strength steel EH32, Category E, for truss flanges.

The computer simulations performed to verify the strength of the examined structure made use of linear-elastic models, while critical loads were calculated using isotropic material models with nonlinear stress/deformation characteristics for the above steels NVA, NV A27, and EH32. A sample material curve for steel NVA is shown in Fig.5. The Young's modulus was assumed equal to $2.06 \mathrm{e} 5 \mathrm{MPa}$, the Poisson's number $\mathrm{v}=0.3$, and the density $7.85 \mathrm{t} / \mathrm{m}^{3}$. The yield points for steels NVA, NV A27 and EH32 were assumed equal to, respectively, $235 \mathrm{MPa}, 265 \mathrm{MPa}$ and $315 \mathrm{MPa}$. For all steels, the tangent plastic hardening modulus was equal to $200 \mathrm{MPa}$.

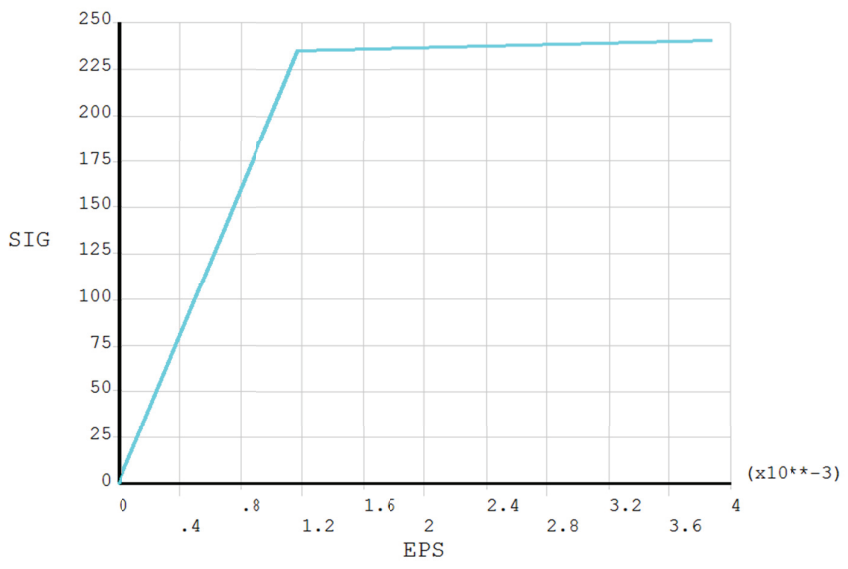

Fig. 5 Stress/deformation curve for the material model of NVA steel

\subsection{LOADS AND BOUNDARY CONDITIONS}

The performed strength analysis took into consideration the following loads and boundary conditions:

a) Self-weight of the structure.

b) Environmental loads (dynamic action of wind, waves, and sea current) corresponding to the maximal loads generated by the heaviest storm on the Baltic Sea in recent 50 years, for the unprotected support location and water depth of up to $40 \mathrm{~m}$. The maximal loads were calculated using CFD codes and the simulation platform STAR$\mathrm{CCM}+$. The assumptions adopted in these calculations are collated in $\mathrm{w}$ Tab.1
Tab. 1 Assumptions for CFD simulations performed to determine environmental loads (wind, waves, sea currents)

\begin{tabular}{|l|c|}
\hline \multicolumn{1}{|c|}{ Name } & Value \\
\hline Type of CFD analysis & Implicit unsteady \\
\hline Time step & $\mathrm{dt}=0.02[\mathrm{~s}]$ \\
\hline Turbulence model & k-epsilon \\
\hline Wave model & Irregular wave (Jonswap) \\
\hline Significant wave height & $\mathrm{H}_{1 / 3}=9.01[\mathrm{~m}]$ \\
\hline Wave period & $\mathrm{T}=11.3[\mathrm{~s}]$ \\
\hline Frequency & $\mathrm{f}=1200[-]$ \\
\hline Peak shape parameter & $\mathrm{p}=4.14[-]$ \\
\hline Spectrum width A & $\mathrm{A}=0.07[-]$ \\
\hline Spectrum width B & $\mathrm{B}=0.09[-]$ \\
\hline Water region depth & $\mathrm{T}_{\mathrm{w}}=40[\mathrm{~m}]$ \\
\hline
\end{tabular}

The strength calculations were performed taking into consideration maximal values of environmental loads obtained from CFD storm simulations, for the irregular wave and Jonswap wave spectrum. A sample free surface shape obtained in the environmental load calculations is shown in Fig. 6, while Fig.7 shows the time history of the total transverse force. In both CFD and FEM calculations, the coherent global coordinate system was used with the origin at the centre of the circle circumscribed about the base bottom. The assumed direction of hydrodynamic loads was the same as that of the horizontal load coming from the wind turbine rotor. The maximal value of the calculated transverse force, corresponding to the average of $1 \%$ of maximal force peaks, was equal to $\mathrm{F}_{\mathrm{x}}=6350 \mathrm{kN}$, while the total moment acting on the structure, which corresponded to the maximal value of $1 \%$ of loads for irregular wave, was equal to $\mathrm{My}=56800 \mathrm{kNm}$.

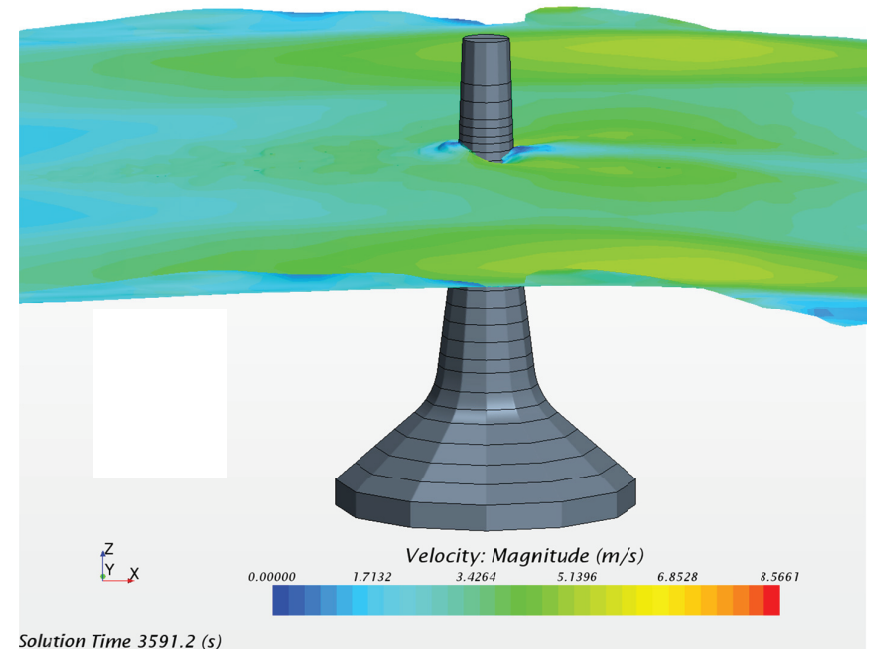

Fig. 6. Sample free surface of the wave being the support load (CFD simulation) 


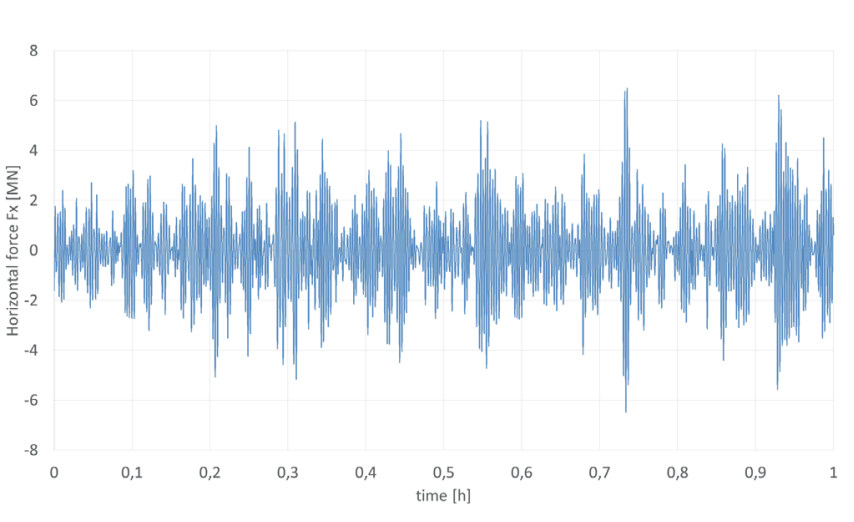

Fig. 7. Time-history of the calculated support load coming from the horizontal force $F_{x}$ generated by the action of irregular wave, for Jonswap wave spectrum (CFD simulation)

c) Loads from the $7 \mathrm{KW}$ wind turbine were assumed taking into account the safety factor $\mathrm{k}=1.35$. The horizontal force from the examined turbine was equal to $\mathrm{F}_{\mathrm{x}}=2.9 \mathrm{MN}$. The remaining loads are protected by confidentiality provisions of the turbine producer and cannot be published.

d) Hydrostatic loads of seawater ( $\rho$ wody $\left.=1.025 \mathrm{t} / \mathrm{m}^{3}\right)$ and inner ballast (pulp, $\rho$ pulpy $=1.7 \mathrm{t} / \mathrm{m}^{3}$ ). The assumed submergence of the column at calm water was $\mathrm{T}_{\mathrm{w}}=40 \mathrm{~m}$. The wave height $\mathrm{H}_{1 / 2}=10 \mathrm{~m}$ was also considered. The conservatively assumed resultant water head was equal to $\mathrm{H}_{\mathrm{w}}=50$ meters, while the hydraulic head of the inner pulp ballast was $\mathrm{H}_{\mathrm{p}}=25 \mathrm{~m}$.

e) The soil stiffness was modelled in accordance with "Annex G" to the standard DNVGL-ST-0126 [46]. Each seabed element within the elliptic area of action was attributed with stiffness corresponding to the structure/ seabed interaction. The effective support area was $\mathrm{A}_{\mathrm{eff}}=896 \mathrm{~m}^{2}$.

\subsection{RESULTS}

The most important results of the presented offshore wind turbine supporting structure strength calculations are the total deflection and the reduced Huber-Mises stresses. The maximal calculated deflection occurs at the nacelle node and is equal to $2268 \mathrm{~mm}$ (Fig.8a), while the maximal total deflection of the support part situated under the intermediate column is observed in the section linking the support with the intermediate column and is equal to $261 \mathrm{~mm}$ (Fig.8b). The maximal values of the reduced Huber-Mises stresses occur in main vertical trusses and are equal to $235 \mathrm{MPa}$ (Fig.9). The calculated values are within the design criteria, according to the standard DNVGL-ST-0126 [46]. Nevertheless, due to non-uniform stress distribution, some modifications were introduced to the design of the structure at the concept development stage - see Section 3.6.
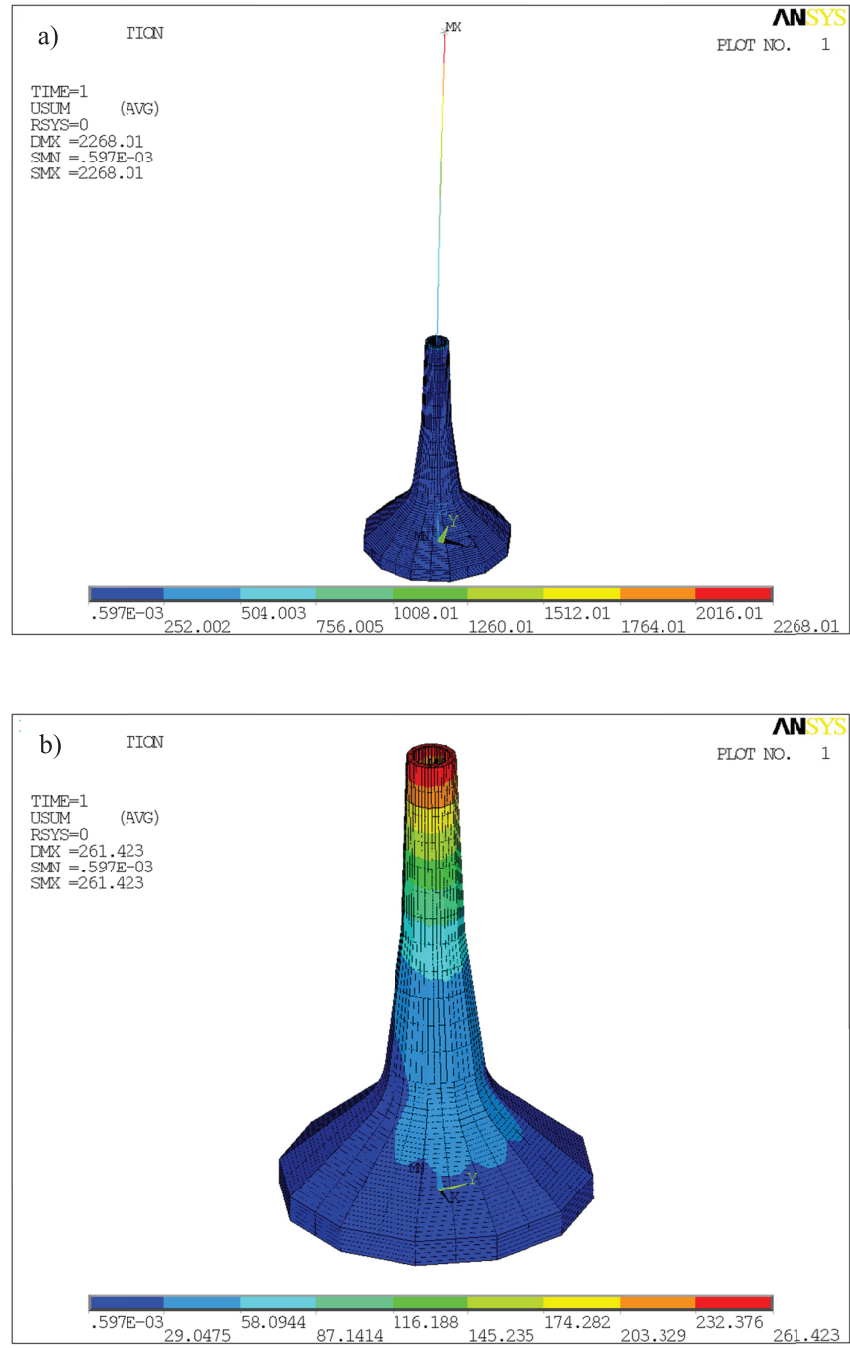

Fig. 8. Total deflection of the offshore wind turbine supporting structure (a), and total support deflection below the intermediate column $(b)[\mathrm{mm}]$

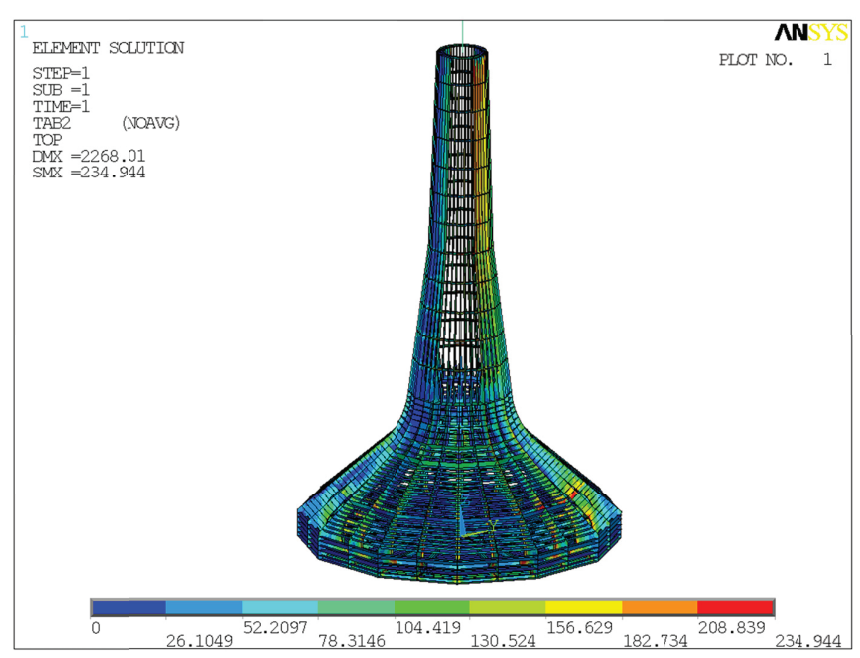

Fig.9. Reduced Huber-Mises stresses in the offshore wind turbine supporting structure [MPa]

It is noteworthy that the maximal stresses refer to a relatively small area of the structure. Its part situated on the 
windward side of the turbine is subjected to relatively low stresses, which results from the nature of loads from waves and wind turbine, always acting in the wind direction.

Additionally, within the framework of the structure strength analysis, the fatigue life was assessed for the most heavily loaded region of the structure. This assessment based on local stress calculations and the so-called local stress approach. Although it was beyond the scope of the required calculations, a conclusion was made that the most heavily loaded node has sufficient fatigue life.

The last results discussed in this article refer to the nonlinear buckling analysis. For the horizontal force Fx, the amplification factor " $n$ " was assumed which was the ratio of the set force and the maximal load of the wind turbine propeller, equal to $F_{x}=2.9 \mathrm{MN}$. The factor $n$ determines how many times the maximal force from the wind turbine was amplified. Figure 10 shows a diagram of maximal turbine node displacement in the horizontal $\mathrm{x}$-axis direction, as a result of $n$-fold amplification of the turbine load. The calculations were conducted at forced displacement input. The obtained results indicate that at the load amounting to 1.44 of the maximal turbine force, the load carrying ability of the structure reaches its limit. The calculations were performed taking into account geometrical and material nonlinearities. The maximal calculated turbine load which can be carried by the structure is $\mathrm{Fx}=4.18 \mathrm{MN}$. Further load increase leads to buckling of the plating and truss webs in the region of structure passage from column to conical base. Local deformations for the critical load are shown in Fig. 11 and Fig. 12.

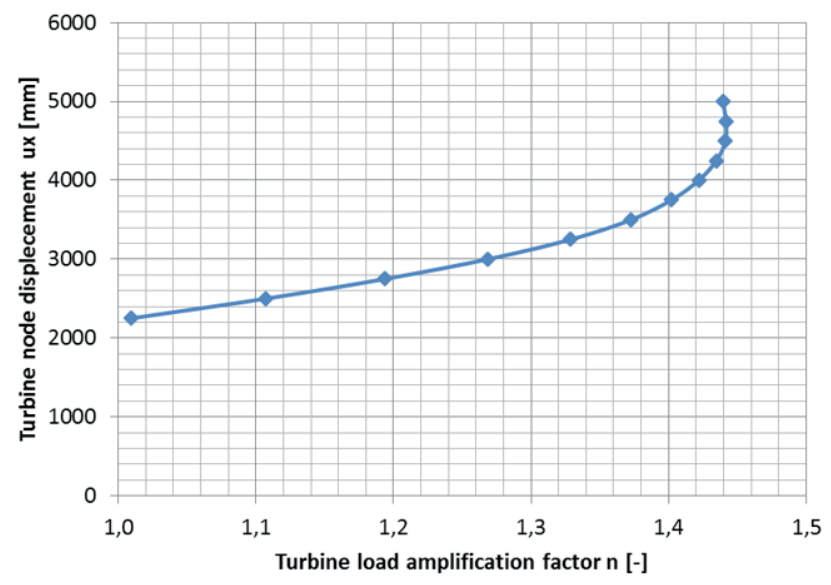

Fig. 10. Maximal turbine node displacement $u_{x}$ vs. turbine load amplification factor $n[-]$

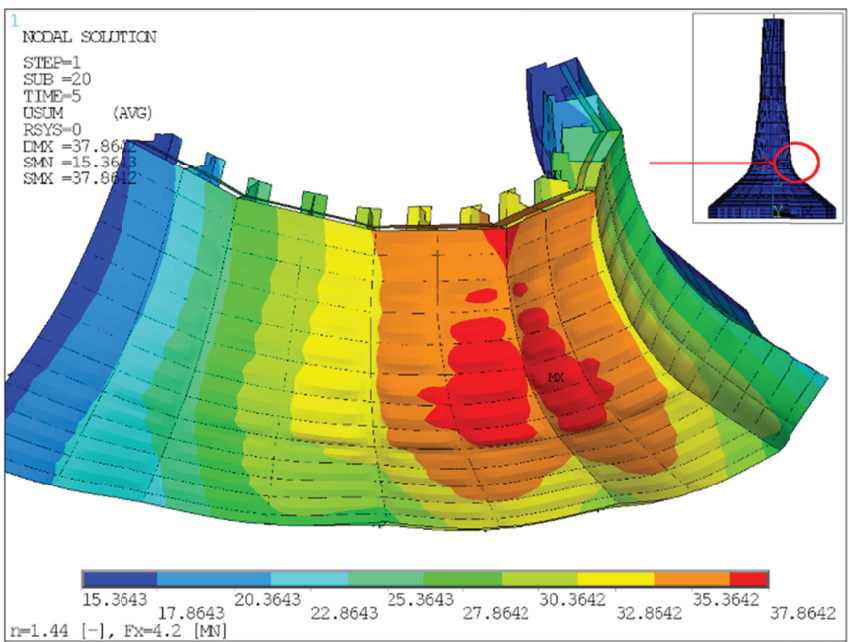

Fig. 11. Local plating deformations for the critical force which initiates buckling

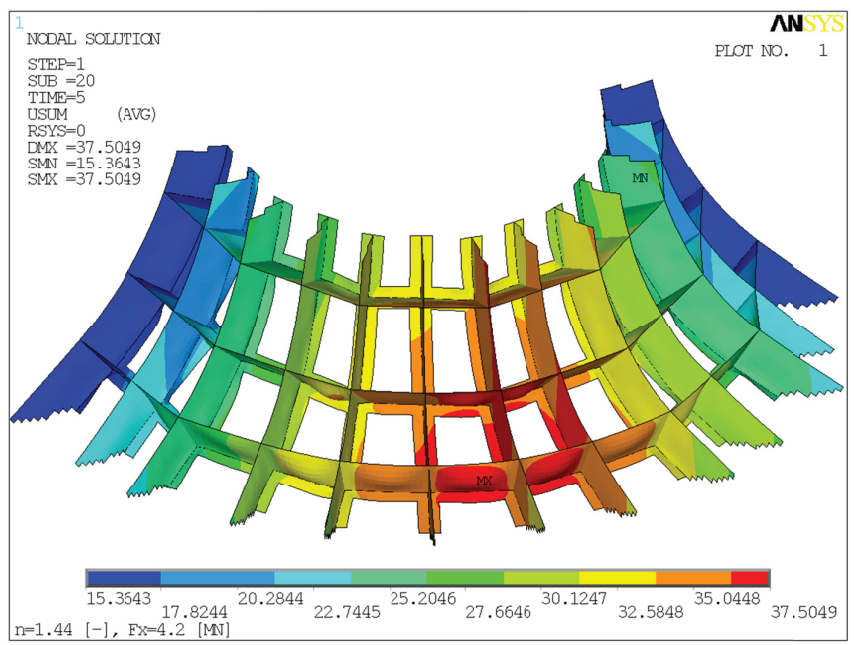

Fig. 12. Maximal truss web deformations for the critical force which initiates buckling

\subsection{GEOMETRICAL SHAPE EVOLUTION OF THE MOST HEAVILY LOADED REGION OF SUPPORT STRUCTURE}

The starting point for developing the concept of the untypical supporting structure for an offshore wind turbine were structural solutions used in modern merchant vessels. These structures consisted of plating stiffened with onedirectional low stiffeners, which were in turn supported by trusses. After preliminary verification calculations, the column deflection level and the local stress distribution in the support were modified. The elements loaded with excessive stresses were reinforced, while those revealing poor cooperation were removed, at the same time preserving smooth characteristic of the longitudinal stiffness of the column. Five calculation variants were analysed for the self-mass change limit equal to $10 \%$. The final effect of the design work performed with the aid of the FEM model based simulation was reducing the maximal total deflections by 
$11 \%$ and the maximal reduced Huber-Mises stresses by $71 \%$. The total mass of the structure was reduced by $9 \%$. The geometry change introduced to the most important bottom truss region is shown in Fig.13. The plating thickness in the bottom region was $20 \mathrm{~mm}$. The thicknesses of bottom truss webs and flanges were equal to, respectively, $15 \mathrm{~mm}$ and 25 mm. Profiles HP430x17 were applied as plating stiffeners. General arrangement of elements in the final version of the structure is shown in Fig.14.
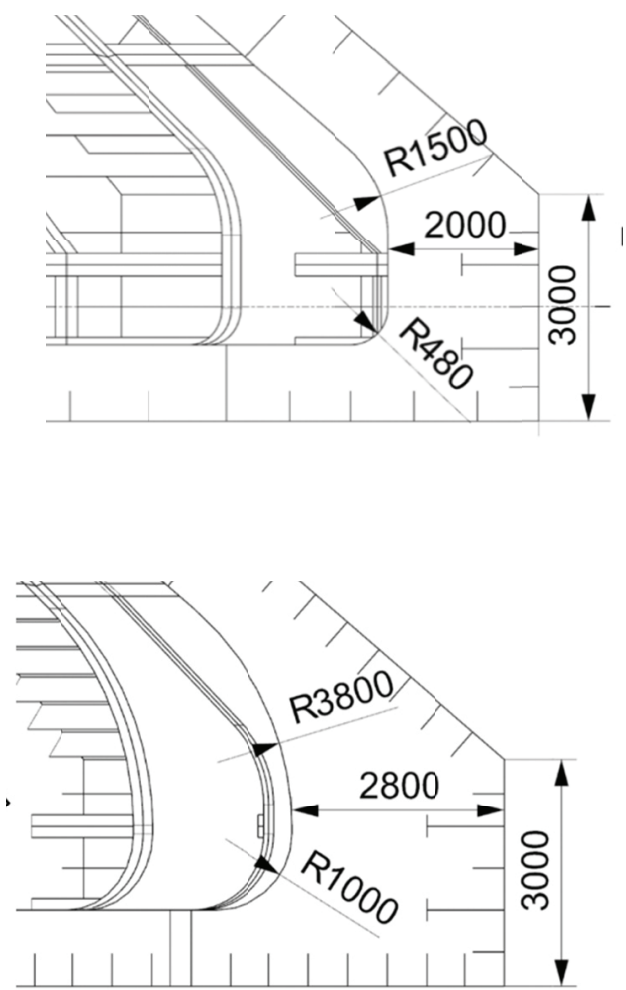

Fig. 13. Geometry changes in the bottom truss region: initial version (upper) and final version (bottom)

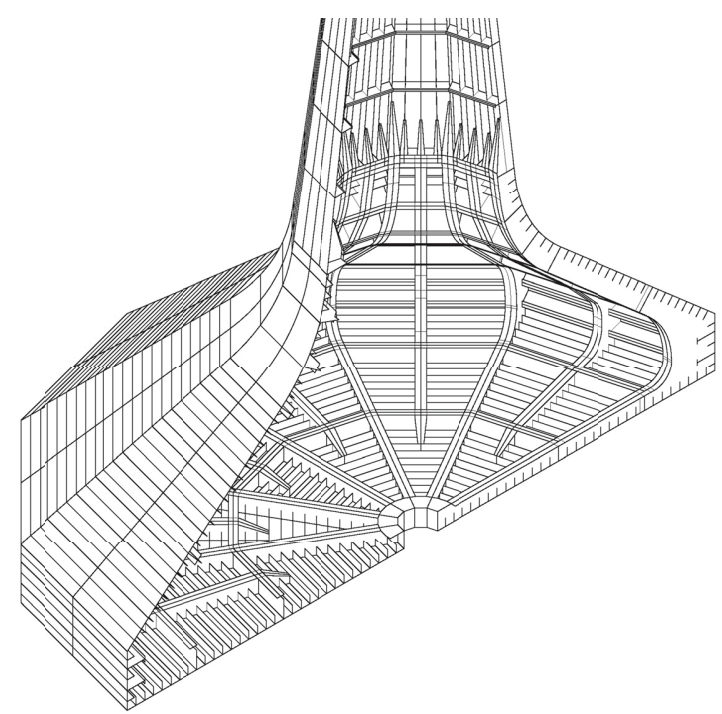

Fig. 14. Explanatory figure of the offshore wind turbine supporting structure (hidden geometry half)

\section{CONCLUSIONS}

The offshore wind power industry is a rapidly developing sector which already plays an important role in electric energy production from renewable sources. However, further technological development of this sector is required to meet market demands concerning reduction of energy production costs. What is essentially needed in this area is working out technical solutions which will provide opportunities for installation of large-power wind turbines, of $10 \mathrm{MW}$ and more, arranged in wind farms situated at a large distance from the seashore and, consequently, on relatively deep waters. A key issue here is turbine immobilisation with respect to the seabed, which can be solved in many ways. There are numerous concepts of supporting structures, including various types of floating platforms, partially submerged platforms, TLP type columns, etc. A possible and potentially favourable solution here can also be a gravitational support. The article presents a concept of a large-size supporting structure of gravitational type which has the form of a steel container. The support can be towed to the place of operation and then submerged by filling ballast tanks with the mixture of sand and water taken from the seabed. The main part of the article is the container structure strength analysis, performed in accordance with the standard DNVGL-ST-0126 [46]. The required numerical calculations were conducted using the Finite Element Method. The obtained results reveal that the structure meets basic strength requirements for the given strength limit. The critical force, which is the load carrying capacity limit for the structure, was assessed. Then the structure design was modified. The introduced modifications allowed to reduce the maximal stress level by $71 \%$, the maximal column deflection by $11 \%$, and the total mass of the structure by $9 \%$. A design modification introduced to the most important bottom region of the structure is presented. After this modification, the mass of the structure was 1250 tonnes. The estimated support production cost is approximately equal to 4 million euro (for the euro/ kg-of-structure coefficient equal to 3.2). It is noteworthy that further structural optimisation is possible, making use of the fact that the loads coming from sea waves and wind turbine are very directional, and not circularly-symmetric as was assumed in the preliminary support concept. In research tests of supports intended for deeper water regions, of high importance is high directionality of maximal design loads. This factor gains even more in importance when we consider enormous dimensions and mass of the structure. Hence, when designing the supporting structure, it is economically profitable to include in the analysis the direction of action of maximal environmental loads, assessed based on statistical hydro-meteorological data for the given water region. This will remarkably reduce the self-mass of the supporting structure and, consequently, costs of its production, transport, installation, and disassembly. 


\section{ACKNOWLEDGEMENTS}

This research was supported by the National Centre for Research and Development (NCBR) under the AQUILO project No. PBS1/A6/8/2012. The numerical calculations were co-financed by CI TASK in Gdansk. Within the framework of hydrodynamic load estimation, the research was co-financed by NCBR under the SmartPS project No. MARTECII/ SmartPS/4/2016. All support is highly appreciated by the author.

\section{BIBLIOGRAPHY:}

1. European Commission, A policy framework for climate and energy in the period from 2020 up to 2030, impact assessment, COM(2014) 15 final, SWD(2014) 15 final, EurLex. 2014

2. European Commission, Communication from the Commission to the European Parliament, the Council, the European Economic and Social Committee and the Committee of the Regions on Launching the public consultation process on a new energy market design, EurLex. 2015

3. Wind in power, 2015 European statistics, European Wind Energy Association, February 2016

4. The European offshore wind industry - key trends and statistics 2015, A report by the European Wind Energy Association, February 2016

5. Annual statistics, WindEurope, 2016

6. Wind Energy Scenarios for 2030, A report by the European Wind Energy Association - August 2015

7. Laszlo Arany, S. Bhattacharya, John Macdonald, S.J. Hogan, Design of monopiles for offshore wind turbines in 10 steps, Soil Dynamics and Earthquake Engineering, Volume 92, January 2017, pp. 126-152, ISSN 0267-7261, http://dx.doi. org/10.1016/j.soildyn.2016.09.024.

8. Swagata Bisoi, Sumanta Haldar, Design of monopile supported offshore wind turbine in clay considering dynamic soil-structure-interaction, Soil Dynamics and Earthquake Engineering, Volume 73, June 2015, pp. 103-117, ISSN 0267-7261, http://dx.doi.org/10.1016/j. soildyn.2015.02.017.

9. A.T. Myers, S.R. Arwade, V. Valamanesh, S. Hallowell, W. Carswell, Strength, stiffness, resonance and the design of offshore wind turbine monopiles, Engineering Structures, Volume 100, 1 October 2015, pp. 332-341, ISSN 0141-0296, http://dx.doi.org/10.1016/j.engstruct.2015.06.021.
10. Hezhen Yang, Yun Zhu, Qijin Lu, Jun Zhang, Dynamic reliability based design optimization of the tripod substructure of offshore wind turbines, Renewable Energy, Volume 78, June 2015, pp. 16-25, ISSN 0960-1481, http:// dx.doi.org/10.1016/j.renene.2014.12.061.

11. B. Yeter, Y. Garbatov, C. Guedes Soares, Fatigue damage assessment of fixed offshore wind turbine tripod support structures, Engineering Structures, Volume 101, 15 October 2015, pp. 518-528, ISSN 0141-0296, http://dx.doi. org/10.1016/j.engstruct.2015.07.038.

12. K.H. Chew, E.Y.K. Ng, K. Tai, M. Muskulus, D. Zwick, Offshore Wind Turbine Jacket Substructure: A Comparison Study between Four-Legged and Three-Legged Designs, J Ocean Wind Energy, 1 (2) (2014), pp. 74-81

13. Sebastian Kelma, Peter Schaumann, Probabilistic Fatigue Analysis of Jacket Support Structures for Offshore Wind Turbines Exemplified on Tubular Joints, Energy Procedia, Volume 80, 2015, pp. 151-158, ISSN 1876-6102, http://dx.doi. org/10.1016/j.egypro.2015.11.417.

14. M.D. Esteban, B. Couñago, J.S. López-Gutiérrez, V. Negro, F. Vellisco, Gravity based support structures for offshore wind turbine generators: Review of the installation process, Ocean Engineering, Volume 110, Part A, 1 December 2015, pp. 281-291, ISSN 0029-8018, http://dx.doi.org/10.1016/j. oceaneng.2015.10.033.

15. W.Z. Lim, R.Y. Xiao, Fluid-structure interaction analysis of gravity-based structure (GBS) offshore platform with partitioned coupling method, Ocean Engineering, Volume 114, 1 March 2016, pp. 1-9, ISSN 0029-8018, http://dx.doi. org/10.1016/j.oceaneng.2015.12.059.

16. Marc Costa Ros, Offshore wind industry review of Gravity Base Foundations (GBSs), Identifying the key barriers to large scale commercialisation of gravity based structures (gbss) in the offshore wind industry, report, The Carbon Trust, October 2015

17. Simon Lefebvre, Maurizio Collu, Preliminary design of a floating support structure for a $5 \mathrm{MW}$ offshore wind turbine, Ocean Engineering, Volume 40, February 2012, pp. 15-26, ISSN 0029-8018, http://dx.doi.org/10.1016/j. oceaneng.2011.12.009.

18. Michael Borg, Maurizio Collu, A Comparison on the Dynamics of a Floating Vertical Axis Wind Turbine on Three Different Floating Support Structures, Energy Procedia, Volume 53, 2014, pp. 268-279, ISSN 1876-6102, http://dx.doi.org/10.1016/j.egypro.2014.07.236.

19. Matthew Hall, Brad Buckham, Curran Crawford, Hydrodynamics-based floating wind turbine support platform optimization: A basis function approach, 
Renewable Energy, Volume 66, June 2014, pp. 559-569, ISSN 0960-1481, http://dx.doi.org/10.1016/j.renene.2013.12.035.

20. M. Collu and M. Borg, 11 - Design of floating offshore wind turbines, In Offshore Wind Farms, Woodhead Publishing, 2016, pp. 359-385, ISBN 9780081007792, http:// dx.doi.org/10.1016/B978-0-08-100779-2.00011-8.

21. Yichao Liu, Sunwei Li, Qian Yi, Daoyi Chen, Developments in semi-submersible floating foundations supporting wind turbines: A comprehensive review, Renewable and Sustainable Energy Reviews, Volume 60, July 2016, pp. 433-449, ISSN 1364-0321, http://dx.doi.org/10.1016/j. rser.2016.01.109.

22. Frank Adam, Thomas Myland, Burkhard Schuldt, Jochen Großmann, Frank Dahlhaus, Evaluation of internal force superposition on a TLP for wind turbines, Renewable Energy, Volume 71, November 2014, pp. 271-275, ISSN 0960-1481, http://dx.doi.org/10.1016/j.renene.2014.05.019.

23. Ali Nematbakhsh, Erin E. Bachynski, Zhen Gao, Torgeir Moan, Comparison of wave load effects on a TLP wind turbine by using computational fluid dynamics and potential flow theory approaches, Applied Ocean Research, Volume 53, October 2015, pp. 142-154, ISSN 0141-1187, http://dx.doi.org/10.1016/j.apor.2015.08.004.

24. Ali M. Abdelsalam, K. Boopathi, S. Gomathinayagam, S.S. Hari Krishnan Kumar, Velraj Ramalingam, Experimental and numerical studies on the wake behavior of a horizontal axis wind turbine, Journal of Wind Engineering and Industrial Aerodynamics, Volume 128, May 2014, pp. 54-65, ISSN 0167-6105, http://dx.doi.org/10.1016/j. jweia.2014.03.002.

25. J.T. Cieslinski, R. Mosdorf, Gas bubble dynamicsexperiment and fractal analysis, International Journal of Heat and Mass Transfer, Volume 48, Issue 9, April 2005, pp. 1808-1818, ISSN 0017-9310, http://dx.doi.org/10.1016/j. ijheatmasstransfer.2004.12.002.

26. Chi-Jeng Bai, Wei-Cheng Wang, Review of computational and experimental approaches to analysis of aerodynamic performance in horizontal-axis wind turbines (HAWTs), Renewable and Sustainable Energy Reviews, Volume 63, September 2016, pp. 506-519, ISSN 1364-0321, http://dx.doi. org/10.1016/j.rser.2016.05.078.

27. Krzysztof J. Kalinski, Marek A. Galewski, Chatter vibration surveillance by the optimal-linear spindle speed control, Mechanical Systems and Signal Processing, Volume 25, Issue 1, January 2011, pp. 383-399, ISSN 0888-3270, http:// dx.doi.org/10.1016/j.ymssp.2010.09.005.

28. Dariusz Mikielewicz, Jarosław Mikielewicz, Joanna Tesmar, Impr
29. oved semi-empirical method for determination of heat transfer coefficient in flow boiling in conventional and small diameter tubes, International Journal of Heat and Mass Transfer, Volume 50, Issues 19-20, September 2007, pp. 3949-3956, ISSN 0017-9310, http://dx.doi.org/10.1016/j. ijheatmasstransfer.2007.01.024.

30. Sebastian Schafhirt, Ana Page, Gudmund Reidar Eiksund, Michael Muskulus, Influence of Soil Parameters on the Fatigue Lifetime of Offshore Wind Turbines with Monopile Support Structure, Energy Procedia, Volume 94, September 2016, pp. 347-356, ISSN 1876-6102, http:// dx.doi.org/10.1016/j.egypro.2016.09.194.

31. K Skalski, A Morawski, W Przybylski, Analysis of contact elastic-plastic strains during the process of burnishing, International Journal of Mechanical Sciences, Volume 37, Issue 5, 1995, pp. 461-472, ISSN 0020-7403, http://dx.doi. org/10.1016/0020-7403(94)00083-V.

32. T.A. Stolarski, Wear of water-lubricated composite materials, Wear, Volume 58, Issue 1, 1980, pp. 103-108, ISSN $0043-$ 1648, http://dx.doi.org/10.1016/0043-1648(80)90215-X.

33. Zhiyu Jiang, Limin Yang, Zhen Gao, Torgeir Moan, Numerical Simulation of a Wind Turbine with a Hydraulic Transmission System, Energy Procedia, Volume 53, 2014, pp. 44-55, ISSN 1876-6102, http://dx.doi.org/10.1016/j. egypro.2014.07.214.

34. Niklas, Karol. "Calculations of notch stress factor of a thinwalled spreader bracket fillet weld with the use of a local stress approach.” Engineering Failure Analysis 45 (2014), pp. 326-338.

35. J.A. Sainz, New Wind Turbine Manufacturing Techniques, Procedia Engineering, Volume 132, 2015, pp. 880-886, ISSN 1877-7058, http://dx.doi.org/10.1016/j.proeng.2015.12.573.

36. C. Dymarski, P. Dymarski, Developing methodology for model tests of floating platforms in low-depth towing tank, Archives of Civil and Mechanical Engineering, Volume 16, Issue 1, January 2016, pp. 159-167, ISSN 1644-9665, http:// dx.doi.org/10.1016/j.acme.2015.07.003.

37. Łuczak M., Manzato S., Peeters B., Branner K., Berring P., Kahsin M.: Updating Finite Element Model of a Wind Turbine Blade Section Using Experimental Modal Analysis Results, Shock and Vibration. -Vol. 2014, iss. 1 (2014), pp.71-82

38. A. Cichański, "The influence of mesh morphology on the SCF in 2D FEM analysis of flat bars with opposite V-notch under tension" in Proceedings of 22nd International Conference on Engineering Mechanics 2016, edited by Igor Zolotarev and Vojtech Radolf, Engineering Mechanics 2016, pp. 110-113 (Svratka, Czech Republic, 2016) 
39. Deja, M. \& Siemiatkowski, M.S., Feature-based generation of machining process plans for optimised parts manufacture, J Intell Manuf (2013) 24: 831. doi:10.1007/s10845-012-0633-X

40. Jiahai Yuan, Chunning Na, Yan Xu, Changhong Zhao, Wind turbine manufacturing in China: A review, Renewable and Sustainable Energy Reviews, Volume 51, November 2015, pp. 1235-1244, ISSN 1364-0321, http://dx.doi.org/10.1016/j. rser.2015.07.048.

41. A. Zieliński, H. Smoleńska, W. Serbiński, W. Kończewicz, A. Klimpel, Characterization of the Co-base layers obtained by laser cladding technique, Journal of Materials Processing Technology, Volumes 164-165, 15 May 2005, pp. 958-963, ISSN 0924-0136, http://dx.doi.org/10.1016/j. jmatprotec.2005.02.093.

42. Magdalena Mieloszyk, Wiesław Ostachowicz, An application of Structural Health Monitoring system based on FBG sensors to offshore wind turbine support structure model, Marine Structures, Volume 51, January 2017, pp. 65-86, ISSN 0951-8339, http://dx.doi.org/10.1016/j. marstruc.2016.10.006.

43. D.J.M. Fallais, S. Voormeeren, E. Lourens, Vibrationbased Identification of Hydrodynamic Loads and System Parameters for Offshore Wind Turbine Support Structures, Energy Procedia, Volume 94, September 2016, pp. 191-198, ISSN 1876-6102, http://dx.doi.org/10.1016/j. egypro.2016.09.222.

44. M. Siemiatkowski, W. Przybylski, Simulation studies of process flow with in-line part inspection in machining cells, Journal of Materials Processing Technology, Volume 171, Issue 1, 10 January 2006, pp. 27-34, ISSN 0924-0136, http://dx.doi.org/10.1016/j.jmatprotec.2005.06.051.

45. Binita Shrestha, Martin Kühn, Adaptation of Controller Concepts for Support Structure Load Mitigation of Offshore Wind Turbines, Energy Procedia, Volume 94, September 2016, pp. 241-248, ISSN 1876-6102, http:// dx.doi.org/10.1016/j.egypro.2016.09.231.

46. Wojciech Litwin, Influence of local bush wear on water lubricated sliding bearing load carrying capacity, Tribology International, Volume 103, November 2016, pp. 352-358, ISSN 0301-679X, http://dx.doi.org/10.1016/j. triboint.2016.06.044.

47. Standard DNVGL-ST-0126, Support structures for wind turbines, DNV GL AS, April 2016

48. VON DER HAAR, C and MARX, S. Design aspects of concrete towers for wind turbines. J. S. Afr. Inst. Civ. Eng. 2015, vol.57, n.4, pp. 30-37. ISSN 2309-8775. http://dx.doi. org/10.17159/2309-8775/2015/v57n4a4
49. DNV-OS-B101, OFFSHORE STANDARD, METALLIC MATERIALS, Det Norske Veritas 2009

50. EN 10025-2 - Non-alloy structural steels, European Committee for Standardization, 2005

\section{CONTACT WITH THE AUTHOR}

\author{
Karol Niklas \\ Gdańsk University of Technology \\ 11/12 Narutowicza St. \\ 80 - 233 Gdańsk \\ Poland
}

